\title{
Mathematical Model of Kazakhstan Economy
}

\author{
Orakbayev E.M. ${ }^{1}$, Boranbayev S.N. ${ }^{1}$, Vashenko M.P. ${ }^{2} \&$ Shananin A.A. ${ }^{2}$ \\ ${ }^{1}$ L.N. Gumilyov Eurasian National University, Kazakhstan \\ ${ }^{2}$ The computer center of Russian Academy of Sciences, department of mathematical modeling of economic \\ systems, Russia \\ Correspondence: Orakbayev E.M., L.N. Gumilyov Eurasian National University, 01008, Kazakhstan.
}

Received: January 9, 2015

Accepted: January 29, 2015

Online Published: July 15, 2015

doi:10.5539/mas.v9n8p160

URL: http://dx.doi.org/10.5539/mas.v9n3px

\begin{abstract}
This article gives a description of a model of the Republic of Kazakhstan modern economy. The model takes into account the specific character of economic brunches and the peculiarities of the competition between the domestic production and imported analogues at the domestic market. A particular attention is paid to the problem of formation of intersectional balance for the enlarged structure of economy. This article also analyzes questions of adaptation of classic approaches offered by Leontiev V.V. to the calculation of input-output coefficients for the brunches that compete with import at the domestic markets.
\end{abstract}

Keywords: mathematical model, market, exporter, importer, trade agent, currency, commercial services, production, commercial bank, national bank, imported goods, domestic goods, salary, government, population

\section{Introduction}

Problem of globalization and of Kazakhstan integration into world economic area became extremely urgent after the introduction of the Customs Union and Kazakhstan's possible accession to the WTO. Welfare of some brunches became dependent on processes with more open foreign trade policy which should be taken into account in short-term planning.

During the period of 2012-2013 import growth rate was much ahead of export growth rate: in 2012 the difference in growth rates was $24 \%$ and after eight months of 2013 it was $10 \%$. This situation threatens those sectors of Kazakhstan economy that are engaged in competition with imported goods on the domestic market and that traditionally employ the major part of the population. For example share of products of animal and plants origin, of ready-made food products in import structure has increased by $0.4 \%$ for 8 months of 2013 , and has decreased by $0.8 \%$ in export structure. Despite the fact that Kazakhstan agriculture, forestry and fish industry involve $25.54 \%$ of the population such changes can cause unwanted negative effects. That is the reason why the problem of agricultural adjustment (volumes and methods of its funding) is one of the most urgent at the negotiations of Kazakhstan with the WTO members.

Apparently Kazakhstan accession to the WTO will have a certain transition phase that will help economy sectors to adjust to new conditions. This makes requested those tools that give opportunity to make not only qualitative but also quantitative evaluations of influence of import rivalry and of import itself on the activity of Kazakhstan economy sectors.

Traditional methods of long-term macroeconomic framework that used to be popular in times of Soviet Union were based on the analysis and compensation of economy subjects' plans. Input-output model by V.V. Leontiev was the main mathematical tool of this adjustment. The quality of medium-term and long-term forecasts has deteriorated with the reduction of planning horizons of economy subjects. Many agents do not plan their activity for more than one year in the context of transition economy and it is impossible to base long-term forecasts on their plans. Forecasting methods that were developed during the period of planned economy turned out to be inadaptable to modern conditions. The only way to solve this problem is to develop methods of mathematical modelling that give opportunity to describe the performance of economy subject taking into account peculiarities of their activity. Countries with developed market economy possess a successful experience of forecasting based on mathematic modelling. In these countries activity of economy subjects does not undergo any rapid changes and could be studied and described by econometric approaches. But models of economic agents that are successfully applied in steady market relations could not be applied to immature market institutions of 
Kazakhstan and at least require a significant adaptation. Econometric relations could be maintained only if development is stable and has no structural changes, because they do not take into account a response on the activity of economy subjects. However Kazakhstan economy hasn't reached the state that can ensure the steady tendency of the development even for medium-term perspective. Commercial banks liquidity crisis of 2008 has proved it; this crisis was accompanied by changes in strategy of bank behavior and by significant fall of production caused by scarcity of working capital. Distinctive features of Kazakhstan and other countries which are in the process of shaping modern market infrastructure are sudden changes of agents' economic strategy. In order to describe the activity of such agents it is necessary to find models that show causal relationships in economy.

The listed problems give us a sound right to claim that long-term development forecasts should be based on correctly structured economy models that would show specific features of the production and circulation and would take into consideration significant responses in economic system. These models could be formed as a part of the approach called systemic analysis of developing economy that is being worked out by scientific school of the member of the RAS A.A. Petrov $(1,2)$ for more than 30 years. The main point of the systemic approach is in the fact that mathematic models include not only a complete description of technologies and technologic relations but also economic instruments of production and circulation arrangement typical for a particular economic system. Thus we have models that give us a self-contained description of the economy development process provided the availability of a set plan for national economic policy. Systemic approach to economy modelling in contrast to any other approaches (for example econometric or an approach based on the models of input-output balance), takes into consideration significant responses in economic system and helps to make models of indirect consequences of important social and economic decisions. Response recording helps to make system oriented qualitative evaluations of economic development programs and to study structural economic changes that could appear as the result of implementation of these programs. The evident advantage of systemic approach methods in the context of possible structural changes of economy and possible alteration of subject's part is the fact that they do not require detailed specification of economic activity. Moreover the applied methods give opportunity to describe qualitative features of agents' behavior and to analyze their possible changes. These methods consider long-term responses depending on ways of national economic adjustment. The listed advantages underline the prospect of system approach application to the problems of medium-term and long-term forecasting.

To sum up everything mentioned above we can claim that the aim of medium-term and long-term forecasting is not the creation of time sequence of macroeconomic indicators but the creation of a tool for efficient and systemic analysis of the consequences of important economic decisions with due regard to the responses. This tool could be materialized as a part of systemic approach to the analysis of a developing economy.

\section{Methodology}

Works of classical authors studying economic science, modern works of foreign and Kazakhstan academic economists and of specialists in the sphere of regional economy and modelling of interregional and intersectional connections represent the methodological basis of the research.

We used methods of systemic analysis, of comparative analysis and composition, of macroeconomic modelling and forecasting, of simulation modelling, methods of quantitative and qualitative studying of the economic processes under investigation and also expert evaluation methods. In this work we used reference materials, tables and schemes. The author used the following methodological approach: taking Kazakhstan input-output balance of 2008 and 2012 as a basis of forecast analysis.

\section{Results}

\subsection{Model Description}

Let us describe general model scheme with its following specifications that reflect model's features. This model distinguishes the following economic agents (or groups of agents):

A1. A group that represent the actual economy sector and service sector. The description of this group (its structure and dividing strategy) will be provided below.

A2. A group that represent national sector. This group includes the following agents:

a. Ministry of Finance, that form a state budget;

b. National Bank (NB).

A3. Households (population). 
A4. Commercial banks.

A5. Trade agents that are responsible for import transactions and retail trading.

This model distinguishes the following markets with action mechanisms described below:

M1. The wholesale market of goods and services. The wholesale market M1 is responsible for intermediate consumption and export of A1 agents' production. M1 market participants are A1 agents and A5 trade agent.

- At the stage of intermediate consumption A1 agents are direct consumers because they purchase the required production factors. A1 agents purchase at M1 market domestic goods and services as well as imported goods and services distributed by A5 trade agent.

○ Export of the production is performed by selling goods at the wholesale market to A5 trade agent who resells them at the outer market.

M2. Retail market. M2 retail market is responsible for the final consumption of A1 agent goods. Participants of this market are: A3 households, A2a government and A5 trade agent. Households and government are consumers while trade agent is a bargainer. Trade agent offers at M2 market both domestic goods purchased at A1 and imported goods.

M3. Foreign exchange market. Participants of this market are:

○ Trade agent who purchases currency to supply import transactions and sells goods to supply export transactions.

○ Government (Ministry of Finance), performing foreign borrowings and their maintenance.

○ National Bank that carry out policy of currency rate.

Household (A3) incomes are formed by the demand of A1 agents on labor and A2a government subsidies.

Government revenues are formed by means of collection of taxes paid by A1 agents, A3 households and A4 commercial banks.

Besides M1, M2 and M3 market campaigns economic agents also provide interaction in the system of monetary circulation. This is in the responsibility of A4 commercial banks:

1. Distribute loans and take deposits from households

2. Grant loans to A1 agents who maintain them afterwards

3. Cooperate with NB that extends or absorbs liquidity of banking system.

Here is more detailed description of A1 agents. Brunches of economy are studied in the context of their cooperation with world markets. It is an attempt to single out those parts of production system and service system that interact with internal and external markets in fundamentally different ways and that have distinct responses to government policy in the sphere of foreign commerce and currency rate. The following sectors are distinguished in this model:

A1-1. "Manufacturing" industries (Sector No.1). The agent represents brunches that do not have export capacity and undergo keen competition with export. Engineering industry is an example of "manufacturing" industry. A1-1 sector is considered to be a generating one, i.e. production of this sector only is used for building new capacities.

A1-2. "Infrastructural" brunches (sector No.2). The agent represents brunches mainly oriented to domestic demand. This sector does not compete with import. Consumption of the third sector as a rule is not flexible in prices. Transportation, power industry, communication are examples of the second sector.

A1-3. "Export" brunches (sector No.3). The agent represents brunches that have high export potential. Prices to this production are formed on external markets.

A1-4. "Commerce and service" sector (sector No.4). The agent represents the sector that includes such brunches as health care and education.

As for formal criteria based on input-output balance (input-output table system) of 2011: 
1. A1-3 sector included brunches which had output export percent exceeding $20 \%$ and export itself exceeded 10 billion tenge in nominal terms.

2. A1-2 sector has combined the following brunches:

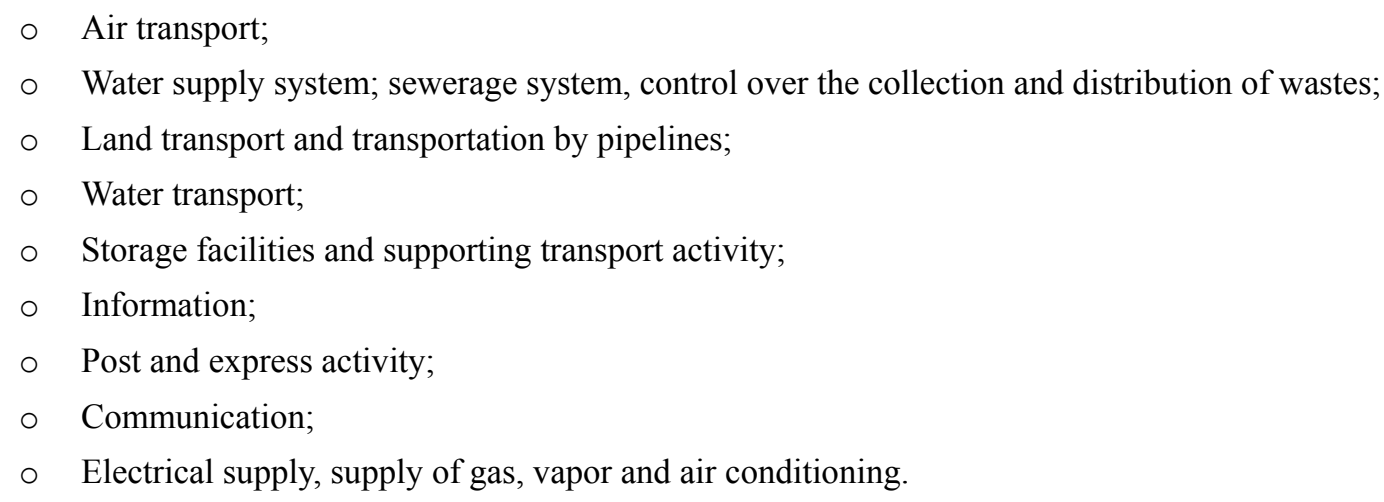

We should underline that export percent relatively to output is unusually high for these brunches and for Air transport, Water supply system, Land transport in particular (for these three brunches it is more than 10\%). However if we calculate net export percent (export - import) relatively to output in order to take into consideration the brunch facilities regarding resources transfer across Kazakhstan territory we will find out that average percent of this indicator is $-2.3 \%$ for the whole $\mathrm{A} 1-2$ sector $(0.4 \%$ for three underlined brunches). This proves the hypothesis that A1-2 sector is oriented on domestic demand.

3. A1-1 sector included manufacturing branches that were not covered by sectors A1-3 and A1-2. Average ratio of import manufacturing costs to output is $10.13 \%$ for this sector.

4. Branches of commercial services has composed A1-4 sector.

\subsection{Description of Markets}

\subsubsection{Description of the Wholesale Market}

A1 manufactures and A5 trade agents interact at the wholesale market. There are two major processes at the market:

1. Exchange (purchase and sale) of goods between manufactures and trade agents to fulfill goals of satisfaction the production needs. Trade agent in this case acts as a supplier of imported goods required for the production. Key feature of this process is input-output balance that describes how many units of imported or domestic goods of any sector are required for manufacturing the production unit of every domestic manufacturer.

2. Distribution of goods, produced by all manufactures except sector 4, to a trade agent for the following resale at the retail market or export. It is considered that sector 4 ("service" sector) distributes its goods independently to population and government at the domestic market.

\subsubsection{Description of the Currency Market}

Purchase and sale of currency takes place at the currency market. Participants of this market are:

1. The trade agent who purchases currency to buy imported goods and sells currency to convert currency gain received from the disposal of export goods.

2. State budget that finances its deficit at the cost of foreign loans (currency sale) and that pays interest charges and pays off an external debt (currency purchase)

3. National Bank that perform currency interventions at the cost of gold and forex reserves in order to maintain the needed foreign exchange.

4. Population.

Let us take GFR for gold and forex reserves of NB, $p_{i}^{e x}$ for index of prices at exported goods of $i$ sector, $p_{1}^{I m}$ 
for index of prices at imported goods of $i$ sector, $Y_{i}$ for the output of $i$ sector, $S_{i}$ for the demand for domestic products of $i$ sector, $S_{1}^{I m}$ for the demand for imported products of $i$ sector, $\varphi$ for the foreign exchange (currency baskets), $H$ for currency purchase by the population.

\section{Currency supply}

$$
E x_{3}(\mathrm{t})=\left(\mathrm{Q}_{3}(\mathrm{t})-\mathrm{S}_{3}(\mathrm{t})_{+} \mathrm{p}_{3}^{e x}(\mathrm{t})\right)
$$

\section{Currency demand}

$$
\begin{aligned}
\operatorname{Im}(\mathrm{t})=\mathrm{C}_{1}^{\mathrm{Im}} p_{1}^{\mathrm{Im}} & \\
& \frac{d G F R}{d t}=\left(\mathrm{Q}_{3}(\mathrm{t})-\mathrm{S}_{3}(\mathrm{t})_{+} \mathrm{p}_{3}^{e x}(\mathrm{t})\right)+H_{G}(t)+r_{G F R} G F R- \\
& -\delta_{G F R} \operatorname{Tax}_{3}^{\varphi}(t)-\frac{1}{\varphi}\left(\mathrm{C}_{1}^{\operatorname{Im}} p_{1}^{\mathrm{Im}}+\sum_{i=1}^{3} a_{i \operatorname{Im}} Y_{i}(t)+\sum_{i=1}^{3} B_{i}^{\mathrm{Im}}(\mathrm{t})+B_{T r}^{\operatorname{Im}}(\mathrm{t})+B_{\operatorname{Im}}^{\operatorname{Im}}(\mathrm{t})+G_{1}^{\operatorname{Im}}(t)\right)
\end{aligned}
$$

\subsection{Description of Economic Sectors}

\subsubsection{Description of Manufacturing Sector}

Manufacturer of I sector does its best to maximize its unreachable discounted revenue by operating maximum stock of goods. Points of goods realization are considered to be events of Poisson stream with the parameter $\lambda$. Volume of goods equal to the minimum of the current manufacturers stock $Y_{1}(t)$ and of maximum sales volume $Y^{*}$ should be disposed during every realization point. Manufacturer produces goods to ensure the maximum stock ( $\zeta(t)$ stands for the ratio of maximum stock to maximum sale volume) and then waits for the next realization point.

Demand for domestic production of the first sector:

$$
S_{1}^{I n t}(t)=\sum_{j=1}^{4} a_{1, j}^{I n t} Y_{j}(t)+T r_{1}^{I n t}(t)+\sum_{j=1}^{4} B_{1, j}(t)+B_{G}^{I n t}(t)
$$

The wholesale price on domestic production of the first sector is set at the wholesale market of the first sector:

$$
\begin{aligned}
& \frac{d p_{1}}{d t}=\alpha p_{1} \frac{S_{1}(\mathrm{t})-\mathrm{Y}_{1}(\mathrm{t})}{\mathrm{Y}_{1}(\mathrm{t})}: \\
& \frac{d \Xi_{1}}{d t}=Y_{1}(\mathrm{t})-S_{1}(\mathrm{t}) .
\end{aligned}
$$

Points of goods realization are considered to be events of Poisson stream with the parameter $\lambda$. Volume of goods equal to the minimum of the current manufacturers stock $\Xi_{1}(\mathrm{t})$ and of maximum sales volume $Y^{*}$ should be disposed during every realization point.

Liquidity limits:

$$
M_{1}=\theta_{1}\left(p_{1} B_{1}(\mathrm{t})+\varphi \mathrm{B}_{1}^{\mathrm{Im}}(\mathrm{t})+\mathrm{rL}_{1}\right)
$$

Inventory balance of the first sector:

$$
\frac{d M_{1}}{d t}=\left(p_{1}-y_{1}\right)\left(Y_{1}(\mathrm{t})-\frac{d \Xi}{d t}\right)-\mathrm{W}_{1}(\mathrm{t})-\mathrm{T}_{1}(\mathrm{t})-r L_{1}(\mathrm{t})-\mathrm{p}_{1} B_{1}(\mathrm{t})-\varphi B_{1}^{\mathrm{Im}}(\mathrm{t})-\operatorname{DIV}(\mathrm{t})
$$

Change of powers:

$$
\frac{d Q_{1}}{d t}=g\left(\frac{B_{1}(\mathrm{t})}{b_{1}}, \frac{B_{1}^{\mathrm{Im}}(\mathrm{t})}{b_{1}^{\operatorname{Im}}}\right)-\mu_{1} Q_{1}
$$


where $\mu_{1}$ is a pace of capacity disposal.

$$
\mathrm{T}_{1}(t)=\left(1-\mathrm{t}_{1}\right)\left(\left(\mathrm{p}_{1}-\mathrm{y}_{1}\right)\left(\mathrm{Y}_{1}(\mathrm{t})-\frac{d \Xi_{1}}{d t}\right)-\mathrm{W}_{1}(\mathrm{t})-\mathrm{rL}_{1}(\mathrm{t})\right)
$$

where $t_{1}$ is profit tax rate, $w_{1}$ is percent of salary in the profit, $y_{1}$ is manufacturing unit cost in I sector

$$
\begin{gathered}
\operatorname{Re} v_{1}(\mathrm{t})=\left(\mathrm{p}_{1}-\mathrm{y}_{1}\right)\left(\mathrm{Y}_{1}(\mathrm{t})-\frac{d \Xi_{1}}{d t}\right) \\
\operatorname{DIV}(\mathrm{t})=v_{1}\left(\operatorname{Re} v_{1}(\mathrm{t})-\mathrm{W}_{1}(\mathrm{t})-\mathrm{T}_{1}(\mathrm{t})-\mathrm{rL}_{1}(\mathrm{t})\right) \\
\frac{d L_{1}}{d t}=U_{1} \mathrm{y} \eta-\lambda\left(\int_{0}^{\left(1+\zeta_{0}\right) \mathrm{Y}^{*}} y x p(x) d x\right)+\left(1-U_{1}\right)\left(\left(1+\zeta_{0}\right) \mathrm{Y}^{*} y\right)
\end{gathered}
$$

\section{Average characteristics of the manufacturing}

$\frac{\lambda Y^{*}}{Q_{1}}$ are characteristics of manufacturing capabilities provided limits of commercial infrastructure are $Y^{*}$

Take:

$$
\begin{gathered}
\varsigma_{0}=\frac{\tau_{0} Q_{1}}{Y^{*}} ; \\
\left(1-\frac{\Delta}{\lambda} \frac{y(\lambda+\Delta)}{p(\lambda+\Delta-r)-y(\lambda+\Delta)}\right)\left(\frac{\lambda}{\lambda+\Delta}\left(1-e^{-\frac{\lambda+\Delta}{\lambda} \varsigma_{0} \frac{\lambda Y^{*}}{\eta}}\right)+e^{-\frac{\lambda+\Delta}{\lambda} \varsigma_{0} \frac{\lambda Y^{*}}{\eta}}\left(e^{\frac{\lambda+\Delta}{\lambda} \frac{\lambda Y^{*}}{\eta}}-\varsigma_{0} \frac{\lambda Y^{*}}{\eta}\right)\right)=1
\end{gathered}
$$

Average capacity utilization:

$$
U_{1}=1-\frac{e^{-\frac{\lambda Y^{*}}{Q_{1}}\left(\xi_{0}+1\right)}}{1-\frac{\lambda Y^{*}}{Q_{1}} \varsigma_{0} e^{-\frac{\lambda Y^{*}}{Q_{1}}}}
$$

, where

$$
\begin{gathered}
\zeta_{0} \in(0,1) ; \\
Q_{1} U_{1}=Y_{1}(\mathrm{t}) . \\
\hat{\Xi}_{1}=Q_{1} U_{1} \frac{p_{1}}{y_{1}}\left(\frac{\lambda+\Delta-\mathrm{r}}{\lambda+\Delta}\right)\left(\frac{1-R}{\lambda}\right)\left(\frac{1-U_{1}}{U_{1}}\right)\left(e^{\frac{\lambda Y^{*}}{R_{1}} \varsigma_{0}}\left(1-\frac{\lambda Y^{*}}{Q_{1}} \varsigma_{0}+e^{\frac{\lambda Y^{*}}{R_{1}}}\right)-\mathrm{r}\right)
\end{gathered}
$$

Production profitability

Assume all profitability conditions are fulfilled:

Profitability of manufacturing

$$
\text { 1. } \begin{aligned}
& \lambda+\Delta>r \\
& Y^{*}>0 \\
& \text { 2. }
\end{aligned}
$$




$$
R=\frac{p-\frac{y(\lambda+\Delta)}{\lambda+\Delta-\mathrm{r}}}{p}
$$

\subsubsection{Description of Extractive Sector}

Let's describe a representative of extractive sector of economy. And for the beginning we will consider three business lines of an agent:

- manufacturing;

- investment;

- financial.

We will assume that operational business of an agent is narrowed down to the development of existing deposits. While developing deposits the agent decides how hard it is necessary to extract resources at the current time variable $I_{3}(t)$. In order to extract the required volume of resources the agent will have to invest some costs the volume of which depends on the "difficulty" - a feature of the deposit and planned production output. For the indicator of the "difficulty" we will take the cost of the first sector production used for extraction of one unit of the resource at the deposit in base-year prices $-z$ parameter. We will assume that agent has an access to the information about density of the cumulative function curve of available oil field development and about the prices for production at the current time $\hat{I}(z, t)$. That means that $\hat{I}(z, t)$ is amount of the resource that could be extracted for $z$ tenge at the moment of time $t$. Agent is always supposed to develop the deposit with the cheapest resource from the point of view of prime costs. Such minimum prime cost at the current time is marked $z_{\text {min }}(t)$.

Resource extraction itself and expenses relating to it are separated in time. That means that after taking a decision that it is necessary to extract $I_{3}(t)$ units of the resource the agent should pay costs according to one diagram and to get resource according to another. Costs diagram is marked as $b_{3}(\tau)$ and extraction diagram is marked as $d_{3}(\tau)$ and it is considered that all costs and extraction take place during a certain period $T_{3}$. I.e. if it is necessary to extract $I_{3}(t)$ resource units with prime cost of the extraction $z_{\min }(t)$ then at the stated time $(t+\tau)$ the agent should pay the sum $p_{1}(t) \cdot p_{1}^{0} \cdot I_{3}(t) \cdot b_{3}(\tau) \cdot z_{\min }(t)$, where $p_{1}(t)$ is an index of wholesale prices on the production of the first sector, and $p_{1}^{0}$ is a price for production unit in base year; thus the agent will get $I_{3}(t) \cdot d_{3}(\tau)$ of resource units.

If $z_{c p}(t)$ stands for the average cost of resource extraction, set to the moment of time $t$ and the formula of which we will give below, then we can register combined capital costs of extracting sector that were charged off at the point of time $t,-C_{A P E X_{3}}(t)$ (unit of measure - tenge of the current year) and total volume of resource production at the point of time $t-Q_{3}(t)$ (unit of measure - output units of the third sector):

$$
\begin{gathered}
\operatorname{CAPEX}_{3}(t)=\operatorname{CAPEX}_{3}^{0}(t)+p_{1}^{0} \cdot \int_{t-T_{3}}^{t} p_{1}(x) \cdot I_{3}(x) \cdot b_{3}(t-x) \cdot z_{c p}(x) d x, \\
Q_{3}(t)=Q_{3}^{0}(t)+\int_{t-T_{3}}^{t} I_{3}(\tau) \cdot d_{3}(t-\tau) \cdot d \tau,
\end{gathered}
$$

where $Q_{3}^{0}(t)$ - is some known function that defines the agent's resource extraction and connected to the 
implementation of investment projects started before the base year and requiring capital costs $C A P E X_{3}^{0}(t)$. Then it can be put down:

$$
\begin{gathered}
Y_{3}(t)=p_{3}^{0} \cdot Q_{3}(t)=p_{3}^{0} \cdot\left(Q_{3}^{0}(t)+\int_{t-T_{3}}^{t} I_{3}(\tau) \cdot d_{3}(t-\tau) \cdot d \tau\right) \text { (tenge of the base year), } \\
B_{3}(t)=B_{3}^{0}(t)+p_{1}^{0} \cdot \int_{t-T_{3}}^{t} I_{3}(x) \cdot b_{3}(t-x) \cdot z_{c p}(x) d x \quad \text { (tenge of the base year). }
\end{gathered}
$$

Agent is supposed to send the extracted resource to domestic outlet first of all and to export the remaining portion with the help of trade agents. If we mark domestic demand for the production of extracting sector as $S_{3}^{\prime}(t)$, then we can express agent's operational profit at the point of time $t,-E B I T D A_{3}(t)$ :

$$
\begin{aligned}
& \operatorname{EBITDA}_{3}(t)=\left(1-n_{3}\right)\left(\left(p_{3}(t) \cdot p_{3}^{0}-\operatorname{tax}_{3}^{1}(t)\right) \cdot \min \left(S_{3}^{\prime}(t), Q_{3}(t)\right)+\right. \\
& \left.+\left(p_{3}^{e x}(t) \cdot p_{3}^{e x, 0}-\operatorname{tax}_{3}^{1}(t)-\operatorname{tax}_{3}^{2}(t)\right) \cdot\left(Q_{3}(t)-S_{3}^{\prime}(t)\right)_{+}-\psi_{3}^{\prime}(t) \cdot Q_{3}(t)\right),
\end{aligned}
$$

where $\psi_{3}^{\prime}(t)$ are the agent's operational costs not including labor expenses to one output unit at the point of time $t, \operatorname{tax}_{3}^{1}(t)-$ tax for resource extraction (tenge of the current year for the production unit of the third sector), $\operatorname{tax}_{3}^{2}(t)$ is export tax (tenge of the current year for production unit of the third sector), $n_{3}$ is labor rate.

Then it can be put down:

operational costs of the extracting sector

$$
\psi_{3}(t)=\left(\sum_{i=1}^{3}\left(p_{i}^{\operatorname{Int} t}(t) \cdot p_{i}^{\operatorname{Int}, 0} \cdot a_{i 3}^{\operatorname{Int} t}+p_{i}^{\mathrm{Im}}(t) \cdot p_{i}^{\mathrm{Im}, 0} \cdot a_{i 3}^{\mathrm{Im}}\right)\right) \cdot Y_{3}(t) \quad \text { (tenge of the current year) }
$$

Financial result of the extracting sector

$$
\begin{gathered}
V_{3}(t)=\left(1-w_{3}\right)\left(\left(p_{3}(t)-\operatorname{tax}_{3}^{1}(t) / p_{3}^{0}\right) \cdot \min \left(S_{3}(t), Y_{3}(t)\right)+\right. \\
\left.+\left(\left(p_{3}^{e x}(t) \cdot p_{3}^{e x, 0}-\operatorname{tax}_{3}^{1}(t)-\operatorname{tax}_{3}^{2}(t)\right) / p_{3}^{0}\right) \cdot\left(Y_{3}(t)-S_{3}(t)\right)_{+}-\psi_{3}(t)\right) \text { (tenge of the current year). }
\end{gathered}
$$

Salary budget of the extracting sector

$W_{3}(t)=\frac{w_{3}}{1-w_{3}} V_{3}(t)$ (tenge of the current year)

We will assume that agent's investment activity is narrowed down to exploration of new deposits. The agent is supposed to ground the investment decisions on the analysis of the current profitability of extraction projects. By current profitability we will mean the following expression $\left(\frac{\tilde{z}(t)}{z_{\min }(t)}-1\right)$, where $\tilde{z}(t)$ is maximum prime cost of resource extraction which maintains investment projects profitable and which is defined in the following ratio:

$$
N P V_{3}(z(t))=\int_{0}^{T_{3}}\left(d(\tau) \cdot n b_{3}(t)-z(t) \cdot p_{1}(t) \cdot b(\tau)\right) \cdot e^{-\tau \cdot W A C C} d \tau=0,
$$

where WACC is a weighted average cost of sector's capital and $n b_{3}(t)$ is average "return" for the sector per 
resource unit:

$n b_{3}(t)=V_{3}(t) \cdot p_{3}^{0} / Y_{3}(t)$ (tenge of the current year for production unit of the third sector).

I.e. $\tilde{z}(t)=\frac{n b_{3}(t) \cdot \int_{0}^{T_{3}} d(\tau) \cdot e^{-\tau \cdot W A C C} d \tau}{p_{1}(t) \cdot \int_{0}^{T_{3}} b(\tau) \cdot e^{-\tau \cdot W A C C} d \tau}$ (tenge of the base year for the production unit of the third sector).

Thus if there is no exploration of new deposits our assumptions about the current profitability and investment activity are shaped by the following ratios:

$$
\begin{gathered}
I_{3}(t)=\hat{I}\left(z_{\min }(t), t\right) \cdot \frac{d z_{\min }(t)}{d t}, \\
\frac{d z_{\min }(t)}{d t}=\chi \cdot\left(\frac{\tilde{z}(t)}{z_{\min }(t)}-1\right), \\
\hat{I}(z, t)=0 \text { where } z<z_{\min }(t), \\
\hat{I}(z, t)=\rho(z) \text { where } z \geq z_{\min }(t),
\end{gathered}
$$

where $\rho(z)$ is some function that imposes the original density of resource allocation according to extraction prime costs, $\chi$ is a constant that defines relation of the agent to projects' profitability.

Then we can define $z_{c p}(t)$ as:

$$
z_{c p}(t)=\frac{z_{\min }(t) \cdot \hat{I}\left(z_{\min }(t), t\right)}{I_{3}(t)} \cdot \frac{d z_{\min }(t)}{d t} .
$$

Now let us describe how exploration of new deposits influences the agent's operational activity. Exploration rate is supposed to be in direct ratio to agent's costs on the development of deposits with some coefficient $v$. Besides the exploration helps to "restore" the curve $\hat{I}(z, t)$, by adding to it new explored resources allocation of which is defined by some function $\varphi(z)$. Thus we can put down:

$$
\begin{gathered}
\hat{I}(z, t)=0 \text { where } z<z_{\text {min }}(t), \\
\frac{\partial \hat{I}(z, t)}{\partial t}=v \cdot C A P E X_{3}(t) \cdot \varphi(z) \text { where } z \geq z_{\text {min }}(t), \\
\hat{I}(z, 0)=\rho(z), \\
I_{3}(t)=v \cdot C A P E X_{3}(t) \cdot \int_{0}^{z_{\min }(t)} \varphi(z) d z+\hat{I}\left(z_{\min }(t), t\right) \cdot \frac{d z_{\min }(t)}{d t} \text { where } \frac{d z_{\min }(t)}{d t}>0, \\
I_{3}(t)=v \cdot \operatorname{CAPEX}_{3}(t) \cdot \int_{0}^{z_{\min }(t)} \varphi(z) d z \text { where } \frac{d z_{\min }(t)}{d t} \leq 0,
\end{gathered}
$$




$$
z_{c p}(t)=\frac{1}{I_{3}(t)} \cdot\left(v \cdot \operatorname{CAPEX}_{3}(t) \cdot \int_{0}^{z_{\min }} z \cdot \varphi(z) d z+z_{\min }(t) \cdot \hat{I}\left(z_{\min }(t), t\right) \cdot \frac{d z_{\min }(t)}{d t}\right) .
$$

We will consider that the agent's financial activity is narrowed down to the questions of financing his/her manufacturing and investment activity and to paying dividends.

We will define financial state of extracting sector according to its account $-M_{3}(t)$ and to the volume of joint debt $L_{3}(t)$.

The agent's account is changed according to the following rule:

$$
\frac{d M_{3}(t)}{d t}=\left(V_{3}(t)-r_{3}^{d} L_{3}(t)-T_{3}^{p}(t)\right)-\alpha_{3}\left(V_{3}(t)-r_{3}^{d} L_{3}(t)-T_{3}^{p}(t)\right)_{+}-B_{3}(t) p_{1}(t)+\frac{d L_{3}(t)}{d t},
$$

where $r_{3}^{d}$ is a cost of the agent's debt, $\alpha_{3}$ is a norm of a distributed profit, $T_{3}^{p}(t)$ is a profit tax, which is defined in the following way:

$$
T_{3}^{p}(t)=\left(1-t_{3}\right)\left(V_{3}(t)-r_{3}^{d} L_{3}(t)\right)_{+},
$$

where $t_{3}$ is a profit tax rate. We assume that the agent should have money at the account to ensure the payment of liability payments: $M_{3}(t)=\theta_{3}\left(V_{3}(t)+r_{3}^{d} L_{3}(t)+T_{3}^{p}(t)\right)$.

This means that account equation is an equation of agent's debt.

\subsubsection{Description of Infrastructural Sector}

Financial result (gross profit) of infrastructural sector is formed by means of distribution of production which has a demand in the value of $S_{2}(t)$ and by means of expenses connected to operational manufacturing charges $\psi_{2}(t)$ and costs on labor paid at the rate of $w_{2}$ :

$$
\begin{aligned}
& V_{2}(t)=\left(1-w_{2}\right)\left(p_{2}(t) \min \left\{S_{2}(t), Y_{2}(t)\right\}-\psi_{2}(t)\right), \\
& \psi_{2}(t)=Y_{2}(t)\left(\sum_{i=1}^{3}\left(p_{i}^{I n t}(t) \cdot p_{i}^{I n t, 0} \cdot a_{i 3}^{I n t}+p_{i}^{\mathrm{Im}}(t) \cdot p_{i}^{\mathrm{Im}, 0} \cdot a_{i 3}^{\mathrm{Im}}\right)\right), \\
& W_{2}(t)=\frac{w_{2}}{1-w_{2}} V_{2}(t) .
\end{aligned}
$$

Financial state of the second sector is defined by money supply of its account $M_{2}(t)$. Sector's account resources are refilled by means of receiving profit from primary activity and money loans. These resources are spent for investments and for payment of principal debt and percents, for dividend payment. Thus equation of the sector's account alteration is the following:

$$
\frac{d M_{2}(t)}{d t}=\left(V_{2}(t)-r_{2}^{d} L_{2}(t)-T_{2}^{p}(t)\right)-\alpha_{2}\left(V_{2}(t)-r_{2}^{d} L_{3}(t)-T_{2}^{p}(t)\right)_{+}-B_{2}(t) p_{1}(t)+\frac{d L_{2}(t)}{d t},
$$

where $L_{2}(t)$ is the sector's joint debt, $r_{2}^{b}$ is the interest rate on debt, $T_{2}^{p}(t)$ is profit tax, $\alpha_{2}$ is a norm of distributed profit for the sector, $B_{2}(t)$ are capital investments of the sector (in real terms).

$$
V_{2}(t)=\left(1-w_{2}\right)\left(p_{2}(t) \min \left\{S_{2}(t), Y_{2}(t)\right\}-Y_{2}(t) \sum_{i} a_{i 2} p_{i}(t)\right)
$$

Whereas

$$
T_{2}^{p}(t)=\left(1-t_{2}\right)\left(V_{2}(t)-r_{2}^{d} L_{2}(t)\right)_{+},
$$

where $t_{2}$ is tax profit rate. 
Process of debt servicing requires all manufacturers to maintain the certain level of the account balance:

$$
M_{2}(t)=\theta_{2} r L_{2}(t),
$$

where $\theta_{2}$ is a liquidity parameter. However manufacturers are supposed to be able only to borrow resources, i.e.

$$
L_{2}(t) \geq 0 .
$$

Here is the description of the investment activity of the second sector. We will consider that production objective of the sector is the maintenance of a certain ratio between supply and demand, i.e.

$$
\frac{S_{2}(t)}{Y_{2}(t)}=\text { const } .
$$

This means that output should change in accordance with the demand, dynamics of which does not depend on the sector's output:

$$
\frac{d Y_{2}(t) / d t}{Y_{2}(t)}=\frac{d S_{2}(t) / d t}{S_{2}(t)}=\gamma(t) .
$$

Taking into account that sector's output is defined by its investment activity and investments "history"

$$
Y_{2}(t)=Y_{2}^{0}(t)+\int_{\min \left\{T_{2}^{I}, t\right\}}^{\min \left\{T_{2}, t\right\}} d_{2}(\tau) I_{2}(t-\tau) d \tau,
$$

Then the required output growth rate is maintained by means of the involvement of the needed investments (here $d_{2}(\tau)$ is a "profile" according to which capacities are placed into service). Investments necessary to satisfy the increasing demand we will find in the ratio:

$$
\begin{gathered}
\frac{d Y_{2}\left(t+T_{2}^{I}\right) / d t}{Y_{2}\left(t+T_{2}^{I}\right)}=\gamma(t) \\
\text { If } t+T_{2}^{I} \geq T_{2} \text {, then, given that } Y_{2}^{0}(t)=0 \quad \forall t>T_{2}, \\
\frac{d Y_{2}\left(t+T_{2}^{I}\right)}{d t}=\int_{T_{2}^{I}}^{T_{2}} d_{2}(\tau) \frac{d I_{2}\left(t+T_{2}^{I}-\tau\right)}{d t} d \tau=-\int_{T_{2}^{I}}^{T_{2}} d(\tau) \frac{d I_{2}\left(t+T_{2}^{I}-\tau\right)}{d \tau} d \tau= \\
=d_{2}\left(T_{2}^{I}\right) I_{2}(t)+\int_{T_{2}^{I}}^{T_{2}} \frac{d d_{2}(\tau)}{d \tau} I_{2}\left(t+T_{2}^{I}-\tau\right) d \tau
\end{gathered}
$$

If $t+T_{2}^{I}<T_{2}$, then

$$
\begin{aligned}
& \frac{d Y_{2}\left(t+T_{2}^{I}\right)}{d t}=\frac{d Y_{2}^{0}\left(t+T_{2}^{I}\right)}{d t}+\int_{T_{2}^{I}}^{t+T_{2}^{I}} d_{2}(\tau) \frac{d I_{2}\left(t+T_{2}^{I}-\tau\right)}{d t} d \tau+d_{2}\left(t+T_{2}^{I}\right) I_{2}(0)= \\
& =\frac{d Y_{2}^{0}\left(t+T_{2}^{I}\right)}{d t}-\int_{T_{2}^{I}}^{t+T_{2}^{I}} d_{2}(\tau) \frac{d I_{2}\left(t+T_{2}^{I}-\tau\right)}{d \tau} d \tau+d_{2}\left(t+T_{2}^{I}\right) I_{2}(0)= \\
& =\frac{d Y_{2}^{0}\left(t+T_{2}^{I}\right)}{d t}+d_{2}\left(T_{2}^{I}\right) I_{2}(t)+\int_{T_{2}^{I}}^{t+T_{2}^{I}} \frac{d d_{2}(\tau)}{d \tau} I_{2}\left(t+T_{2}^{I}-\tau\right) d \tau
\end{aligned}
$$

That is why 


$$
\begin{gathered}
\frac{d Y_{2}\left(t+T_{2}^{I}\right)}{d t}=\frac{d Y_{2}^{0}\left(t+T_{2}^{I}\right)}{d t}+d_{2}\left(T_{2}^{I}\right) I_{2}(t)+ \\
+\int_{T_{2}^{I}}^{\min \left\{t+T_{2}^{I}, T_{2}\right\}} \frac{d d_{2}(\tau)}{d \tau} I_{2}\left(t+T_{2}^{I}-\tau\right) d \tau= \\
=\gamma(t)\left(Y_{2}^{0}\left(t+T_{2}^{I}\right)+\int_{T_{2}^{I}}^{\min \left\{T_{2}, t\right\}} d_{2}(\tau) I_{2}\left(t+T_{2}^{I}-\tau\right) d \tau\right) \\
I_{2}(t)=\frac{1}{d_{2}\left(T_{2}^{I}\right)}\left(\int_{T_{2}^{I}}^{\min \left\{t+T_{2}^{I}, T_{2}\right\}} I_{2}\left(t+T_{2}^{I}-\tau\right)\left(\gamma(t) d_{2}(\tau)-\frac{d d_{2}(\tau)}{d \tau}\right) d \tau+\right. \\
\left.+\gamma(t) Y_{2}^{0}\left(t+T_{2}^{I}\right)-\frac{d Y_{2}^{0}\left(t+T_{2}^{I}\right)}{d t}\right)
\end{gathered}
$$

Investment activity sets capital costs of the sector according to the following rule:

$$
B_{2}(t)=\int_{T_{2}^{I}}^{T_{2}} b_{2}(\tau) I_{2}(t-\tau) d \tau .
$$

Here $b_{2}(\tau)$ is a "profile" according to which costs connected to investments are made.

The sector needs to raise enough capital for financing the investment program in order to fulfill the planned investment projects. Some resources will be received as sector's undistributed profits and some capital will be borrowed. Sector's operation of undistributed profit is limited by the requirements for dividend payment.

The sector's demand for borrowed funds could be taken from the equation (3.16)by putting the expression (3.19) into it, provided fixed investment costs:

$$
\begin{aligned}
& \frac{d L_{2}(t)}{d t}=\frac{1}{1-\theta_{2} r_{2}^{b}}\left(p_{1}(t) B_{2}(t)-\left(1-t_{2}\right)\left(V_{2}(t)-r_{2}^{b} L_{2}(t)\right)+\right. \\
& \left.+\alpha_{2}\left(1-t_{2}\right)\left(V_{2}(t)-r_{2}^{b} L_{2}(t)\right)_{+}\right) .
\end{aligned}
$$

On the other hand capital supply depends on profitability of the sector's investment projects. The borrowed capital supply could be described by the following ratio:

$$
\frac{d L_{2}(t)}{d t}=\zeta(z) p_{1}(t) B_{2}(t)
$$

where $z$ is the sector's profitability evaluation, and function $\zeta(z)$ satisfies the following ratios: $0 \leq \zeta(z)<1$, $\dot{\zeta}(z) \geq 0$. Thus the market is supposed to be ready to finance some part from the required capital costs, besides the more profitability of the projects the bigger part could be financed by means of the loan.

Profitability evaluation is based at the price of investment projects given to the current point of time $t$, calculated according to the stream of payments for the project provided that prices on production of all brunches would not change. Thus net (i.e. except for costs) flow from payments for the project which started at the point of time $t$, happening at the point of time $(t+\tau)$ could be put down as

$$
C F_{2}(t, \tau)=n b_{2}(t) \cdot d_{2}(\tau)-p_{1}(t) \cdot b_{2}(\tau),
$$

where $n b_{2}(t)$ is the return of the investment project per a production unit including operational costs, i.e. 


$$
n b_{2}(t)=\left(1-w_{2}\right)\left(p_{2}(t)\left(\min \left\{\frac{S_{2}(t)}{Y_{2}(t)}, 1\right\}-a_{22}\right)-\sum_{i \neq 2} a_{i 2} p_{i}(t)\right) .
$$

As a matter of fact $V_{2}(t) / Y_{2}(t)=n b_{2}(t)$.

Provided the discount rate is $r$ then the net cost of investment projects stated to the point of time $t$ is defined as

$$
N P V_{2}(r, t)=\int_{0}^{T_{2}} C F_{2}(t, \tau) e^{-r \tau} d \tau
$$

i.e. $\quad N P V_{2}(r, t)=\int_{0}^{T_{2}}\left(n b_{2}(t) \cdot d_{2}(\tau)-p_{1}(t) \cdot b_{2}(\tau)\right) e^{-r \tau} d \tau$. Then for the evaluation of investment projects profitability we take the value

$$
\hat{r}: N P V_{2}(\hat{r}, t)=0 \text {. }
$$

In order to receive the loan capital required for the fulfillment of investment program the sector should ensure a certain level of investment projects profitability, i.e. equations (3.29) and (3.28) should be integrated. Profitability conditions required for the balance of supply and demand of the borrowed funds could be defined after equating the expressions for $\frac{d L_{2}(t)}{d t}$ from 错误! 未找到引用源。 and 错误! 未找到引用源。：

$$
\begin{aligned}
& \hat{z}(t)=\zeta^{-1}\left(\frac{p_{1}(t) B_{2}(t)-\left((1-t)\left(1-n_{2}\right)(1-w) V_{2}(t)-(1-t) r_{2} L_{2}(t)\right)}{p_{1}(t) B_{2}(t)\left(1-\theta_{2} r_{2}\right)}+\right. \\
& \left.+\frac{k_{N}\left((1-t)\left(1-n_{2}\right)(1-w) V_{2}(t)-(1-t) r_{2} L_{2}(t)\right)_{+}}{p_{1}(t) B_{2}(t)\left(1-\theta_{2} r_{2}\right)}\right)
\end{aligned}
$$

Such profitability is required for investment projects of the sector, i.e. it is necessary to follow:

$$
N P V_{2}(\hat{z}(t), t)=0 \text {. }
$$

The sector could accomplish the equation by increasing prices on its production. Target level of prices could be defined by detailing:

$$
\begin{gathered}
\int_{0}^{T_{2}}\left(n b_{2}(t) \cdot d_{2}(\tau)-p_{1}(t) \cdot b_{2}(\tau)\right) e^{-\hat{z}(t) \tau} d \tau=0, \\
n b_{2}(t)=\frac{p_{1}(t) \int_{0}^{T_{2}} b_{2}(\tau) e^{-\hat{z}(t) \tau} d \tau}{\int_{0}^{T_{2}} d_{2}(\tau) e^{-\hat{z}(t) \tau} d \tau}, \\
\hat{p}_{2}(t)=\frac{Y(t)}{S(t)-a_{22} Y(t)}\left(\sum_{i \neq 2} a_{i 2} p_{i}(t)+\frac{p_{1}(t) \int_{0}^{T_{2}} b(\tau) e^{-\hat{z}(t) \tau} d \tau}{\int_{0}^{T_{2}} d(\tau) e^{-\hat{z}(t) \tau} d \tau}\right) .
\end{gathered}
$$

Note that level of prices $\hat{p}_{2}(t)$ is defined according to the assumptions that disregard the fact that $V_{2}(t)$ 
increases together with $p_{2}(t)$ (and vice versa). As a matter of fact when the sector needs extra borrowed funds in order to fulfill the investment program, i.e. when the right part (3.28) is positive, the evaluation $\hat{p}_{2}(t)$ of price level required to attract the loan capital turns out to be excessive. That is why actual development of prices for the sector's production could be put down as:

$$
\frac{d p_{2}(t)}{d t}=\pi \cdot\left(\hat{p}_{2}(t)-p_{2}(t)\right),
$$

where $\pi$ is quite large parameter responsible for compliance of prices with the target level. Actual parameters of the sector $V_{2}(t)$ and $L_{2}(t)$ (from the equation (3.37)) are defined according to the price level determinate. And actual value of the sector's distributed profit is defined by the equation (3.16) and ratio (3.19)

$$
D I V_{2}(t)=V_{2}(t)-(1-t) r_{2} L_{2}(t)-T_{2}^{p}(t)-p_{1}(t) B_{2}(t)+\frac{d L_{2}(t)}{d t}(1-\theta r) .
$$

\subsubsection{Description of Commercial Services Sector}

Service sector is characterized by significant expenses on the maintenance of capacities and by "shadow" element of the price that sets the difference between costs on the service sector production for other economic agents and revenues coming to the sector's account.

Price on the sector's production $p_{4}=\hat{p}_{4}+\tilde{p}_{4}$, where $\tilde{p}_{4}$ are official rates, which is controlled by the plan in accordance with the expenses $\tilde{p}_{4}=\left(1+\delta_{4}\right) \sum_{j=1}^{4} a_{j 4} p_{j}, \hat{p}_{4}$ shadow element (corruptive) of the price that is defined by demand excesses $Y_{4}$ over the sector's capacity $Q_{4}$. Alteration of the "shadow" element of the price:

$$
\frac{d \hat{p}_{4}}{d t}=\alpha \frac{Y_{4}-Q_{4}}{Q_{4}} \hat{p}_{4}
$$

Demand for the sector's services:

$$
Y_{4}(\mathrm{t})=\sum_{j=1}^{4} a_{j 4} Y_{j}(\mathrm{t})+a_{4 T r}\left(\mathrm{C}_{1}^{I n t}+\mathrm{C}_{1}^{\mathrm{Im}}\right)+\mathrm{C}_{4}(\mathrm{t})+\mathrm{G}_{4}(\mathrm{t})+\widehat{\mathrm{b}}_{T r} I_{T r}
$$

Here $C_{4}$ is household demand for the services, $G_{4}$ is demand for the government services, $\widehat{b}_{T r} I_{T r}$ is commercial demand for the services necessary for the development of its capacity, $\sum_{j=1}^{4} a_{j 4} Y_{j}(\mathrm{t})+a_{4 T r}\left(\mathrm{C}_{1}^{\mathrm{Int}}+\mathrm{C}_{1}^{\mathrm{Im}}\right)$ operating demand for the services of manufacturing sectors, of commerce and importers.

Account is defined by the limits of liquidity:

$$
M_{4}=\theta_{4}\left(\mathrm{w}_{4} Q_{4}+\sum_{i=1}^{4} p_{i} a_{i 4} \mathrm{Y}_{4}\right)
$$

where $w_{4}$ is official labor rate at the service sector.

Account is changed by means of

- Cash inflow for the provided services $\tilde{p}_{4} Y_{4}$;

- Payment of financial expenses $\sum_{i=1}^{4} a_{i 4} p_{i} Y_{4}$, related to rendering of services;

- Tax payments $\mathrm{t}_{4}\left(\tilde{p}_{4}-\sum_{i=1}^{4} a_{i 4} p_{i}\right) \mathrm{Y}_{4}$;

- Payment of salaries to the sector's employees $\mathrm{w}_{4} Q_{4}$;

- Payment of investments in the development of the service sector $p_{1} b_{4} I_{4}$; 
- transfers $\mathrm{F}_{4}=\left(-\left(\tilde{p}_{4}-\sum_{i=1}^{4} a_{i 4} p_{i}\right) \mathrm{Y}_{4}\left(1-\mathrm{t}_{4}\right)+\mathrm{w}_{4} Q_{4}\right)_{+}$.

Thus we come to

$$
\frac{d M_{4}}{d t}=\left(\left(\tilde{p}_{4}-\sum_{i=1}^{4} a_{i 4} p_{i}\right) \mathrm{Y}_{4}\left(1-\mathrm{t}_{4}\right)-\mathrm{w}_{4} Q_{4}\right)_{+}-p_{1} b_{4} I_{4}
$$

This equation with consideration of liquidity limits defines the volume of investments into the development of the service sector capacity $p_{1} b_{4} I_{4}$.

We will assume that capacity development is defined by the following equation

$$
\frac{d Q_{4}}{d t}=I_{4}-\mu_{4} Q_{4}
$$

where $\mu_{4}$ is the rate of the retirement of the service sector capacities.

Revenues distributed by the household in the result of the service sector activity are the following

$$
W_{4}(\mathrm{t})=w_{4} Q_{4}+\hat{p}_{4} Y_{4} .
$$

Taxes paid by the sector are

\subsubsection{Description of the Commercial Sector}

$$
\operatorname{Tax}_{4}(\mathrm{t})=\mathrm{t}_{4}\left(\tilde{p}_{4}-\sum_{i=1}^{4} p_{i} a_{i 4}\right) \mathrm{Y}_{4}
$$

Domestic production dealer competes with the importer at the market of the first sector goods. We will assume that there is Nash equilibrium between them. The strategy of the domestic production dealer is to set a retail price $\hat{p}_{1}^{\text {Int }}$ to the goods of the first sector, and the importer's strategy is to set a price to imported consumer goods $\hat{p}_{1}^{\operatorname{Im}}$. The domestic production dealer maximizes his/her profit $\left(\hat{p}_{1}^{\text {Int }}-\breve{p}_{1}^{\text {Int }}\right) C_{1}^{\text {Int }}\left(\hat{p}_{1}^{\text {Int }}, \hat{p}_{1}^{\mathrm{Im}}\right)$, and importer his/her profit $\left(\hat{p}_{1}^{\mathrm{Im}}-\breve{p}_{1}^{\mathrm{Im}}\right) C_{1}^{\mathrm{Im}}\left(\hat{p}_{1}^{\operatorname{Int}}, \hat{p}_{1}^{\mathrm{Im}}\right)$.

Here $\breve{p}_{1}^{\text {Int }}=p_{1}+\sum_{i=1}^{4} a_{i T r} p_{i}$ is a prime cost of the production unit of the domestic production dealer, $\breve{p}_{1}^{\mathrm{Im}}=p^{\mathrm{Im}}+\sum_{i=1}^{4} a_{i \mathrm{Im}} p_{i}$ is an importer's prime cost, $p^{\mathrm{Im}}$ is a purchase value of imported goods calculated according to the exchange rate, and

$$
\begin{aligned}
& \mathrm{C}_{1}^{\text {Int }}\left(\hat{p}_{1}^{\text {Int }}, \hat{p}_{1}^{\mathrm{Im}}\right)=\frac{\varphi}{\left[\left(\mathrm{A}_{1}\left(\hat{p}_{1}^{\text {Int }}\right)^{\delta}\right)^{\frac{1}{1+\delta}}+\left(\mathrm{A}_{2}\left(\hat{p}_{1}^{\mathrm{Im}}\right)^{\delta}\right)^{\frac{1}{1+\delta}}\right]} \mathrm{A}_{1}^{\frac{1}{1+\delta}}\left(\hat{p}_{1}^{\text {Int }}\right)^{-\frac{1}{1+\delta}} \\
& \mathrm{C}_{1}^{\mathrm{Im}}\left(\hat{p}_{1}^{\text {Int }}, \hat{p}_{1}^{\mathrm{Im}}\right)=\frac{\varphi}{\left[\left(\mathrm{A}_{1}\left(\hat{p}_{1}^{\text {Int }}\right)^{\delta}\right)^{\frac{1}{1+\delta}}+\left(\mathrm{A}_{2}\left(\hat{p}_{1}^{\mathrm{Im}}\right)^{\delta}\right)^{\frac{1}{1+\delta}}\right]} \mathrm{A}_{1}^{\frac{1}{1+\delta}}\left(\hat{p}_{1}^{\mathrm{Im}}\right)^{-\frac{1}{1+\delta}}
\end{aligned}
$$

according to the demand function for the imported goods depending on their prices. These functions describe the substitution of the domestic products and imported products in the structure of the household consumption assuming that they are described by the model of a representative, rational consumer who in case of budget limitation $\hat{p}_{1}^{\operatorname{Int} x}+\hat{p}_{1}^{\mathrm{Im}} y \leq \varphi, x \geq 0, y \geq 0$ maximizes the utility function 


$$
u(x, y)=\left[A_{1} x^{-\delta}+A_{2} y^{-\delta}\right]^{-\frac{1}{\delta}}, \delta \in[-1,0],
$$

where $x$ is the consumption of the first sector domestic goods, $y$ is the consumption of the imported goods, $\varphi$ are the household expenses to the first sector goods and their imported analogs.

There is no difficulty to show that

$$
\begin{aligned}
& C_{1}^{I n t}\left(\hat{p}_{1}^{I n t}, \hat{p}_{1}^{I m}\right)=\frac{\varphi}{q\left(\hat{p}_{1}^{I n t}, \hat{p}_{1}^{I m}\right)} \frac{\partial q\left(\hat{p}_{1}^{I n t}, \hat{p}_{1}^{I m}\right)}{\partial \hat{p}_{1}^{I n t}}, \\
& C_{1}^{I m}\left(\hat{p}_{1}^{I n t}, \hat{p}_{1}^{I m}\right)=\frac{\varphi}{q\left(\hat{p}_{1}^{I n t}, \hat{p}_{1}^{I m}\right)} \frac{\partial q\left(\hat{p}_{1}^{I n t}, \hat{p}_{1}^{I m}\right)}{\partial \bar{p}_{1}^{I m}},
\end{aligned}
$$

where

$$
q\left(\hat{p}_{1}^{\operatorname{Int}}, \hat{p}_{1}^{\mathrm{Im}}\right)=\left[\left(A_{1}\left(\hat{p}_{1}^{\operatorname{Int}}\right)^{\delta}\right)^{\frac{1}{1+\delta}}+\left(A_{2}\left(\hat{p}_{1}^{\operatorname{Im}}\right)^{\delta}\right)^{\frac{1}{1+\delta}}\right]^{1+\frac{1}{\delta}}
$$

Yang conversion of the utility function $u(x, y)$. In this case the only Nash equilibrium is possible

$$
\begin{aligned}
& \hat{p}_{1}^{\text {Int }}=-\frac{\breve{p}_{1}^{I n t}}{\delta}\left((1+\delta)^{-(1+\delta)}\left(\frac{A_{1}\left(\breve{p}_{1}^{I n t}\right)^{\delta}}{A_{2}\left(\breve{p}_{1}^{\operatorname{Im}}\right)^{\delta}}\right)+1,\right. \\
& \hat{p}_{1}^{\operatorname{Im}}=-\frac{\breve{p}_{1}^{\operatorname{Im}}}{\delta}\left((1+\delta)^{-(1+\delta)}\left(\frac{A_{2}\left(\breve{p}_{1}^{\operatorname{Im}}\right)^{\delta}}{A_{1}\left(\breve{p}_{1}^{I n t}\right)^{\delta}}\right)+1\right) .
\end{aligned}
$$

\subsubsection{The Commerce Sector of Domestic Goods}

The commerce capacity is $Q_{T r}(\mathrm{t}) \geq \mathrm{C}_{1}^{I n t}(\mathrm{t})$, we will consider that $Q_{T r}(\mathrm{t})=\max _{\tau \leq t} \mathrm{C}_{1}^{I n t}(\tau)$.

We will assume that the dealer has the capacity $Q_{T r}$ (for example, retail space) for the products realization. Capacities has a rate $\mu$. The dealer injects capital $I_{T r}(t)$ to the capacity creation. In this case the capacities will change according to equation

Equation of the capacity development:

$$
\Rightarrow I_{T r}=\frac{d Q_{T r}}{d t}+\mu_{T r} Q_{T r}(\mathrm{t})
$$

Take:

- $\quad p_{1}^{\text {Int }}(t)$ for prices at the consumer market;

- $\quad p_{1}(t)$ for prices at the products of the first sector;

- $\quad b_{T r}$ for capital ratio of the capacity unit.

Loan indebtedness:

$$
\frac{d L_{T r}}{d t}=l\left(p_{1} b_{T r}+p_{4} \hat{b}_{T r}\right) I_{T r}
$$

Revenues distributed by the households as an activity result: 


$$
H_{T r}(\mathrm{t})=\left(\hat{\mathrm{p}}_{1}^{\text {Int }}(\mathrm{t})-\mathrm{p}_{1}(\mathrm{t})-\sum_{i=1}^{4} a_{i T r} p_{i}\right) \mathrm{C}_{1}^{I n t}(t)-\mathrm{r}_{T r} L_{T r}(\mathrm{t})-(1-l)\left(\mathrm{p}_{1}(\mathrm{t}) \mathrm{b}_{T r}+p_{4} \hat{b}_{T r}\right) I_{t r}-\operatorname{Tax}_{T r}(\mathrm{t})
$$

where $H_{T r}(t)$ is a profit received by the dealer at the point of time $t$ (in case if $H_{T r}(t)$ is negative, the dealer is supposed to put up his/her capital to the business development).

$$
\operatorname{Tax}(\mathrm{t})=t_{T r}\left(\left(\hat{\mathrm{p}}_{1}^{\text {Int }}(\mathrm{t})-\mathrm{p}_{1}(\mathrm{t})-\sum_{i=1}^{4} a_{i T r} p_{i}\right) \mathrm{C}_{1}^{\text {Int }}(\mathrm{t})\right.
$$

3.3.7 The Commerce Sector of Imported Goods

Importer's capacity:

$$
Q_{\mathrm{Im}}(\mathrm{t}) \geq \mathrm{C}_{1}^{\mathrm{Im}}(\mathrm{t}) \text {, assume that } Q_{\mathrm{Im}}(\mathrm{t})=\max _{\tau \leq t} \mathrm{C}_{1}^{\mathrm{Im}}(\tau)
$$

Capacity development equation:

$$
\Rightarrow I_{\mathrm{Im}}=\frac{d Q_{\mathrm{Im}}}{d t}+\mu_{\mathrm{Im}} Q_{\mathrm{Im}}(\mathrm{t})
$$

Loan indebtedness

$$
\frac{d L_{\mathrm{Im}}}{d t}=l_{\mathrm{Im}}\left(p_{1} b_{\mathrm{Im}}+p_{4} \hat{b}_{\mathrm{Im}}\right) I_{\mathrm{Im}}
$$

Revenues distributed by households as a result of importer's commercial activity

$$
\begin{gathered}
H_{\mathrm{Im}}(\mathrm{t})=\left(\hat{\mathrm{p}}_{1}^{\mathrm{Im}}(\mathrm{t})-\mathrm{p}^{\mathrm{Im}}(\mathrm{t})-\sum_{i=1}^{4} a_{i T r} p_{i}\right) \mathrm{C}_{1}^{\mathrm{Im}}(t)-\mathrm{r}_{\mathrm{Im}} L_{\mathrm{Im}}(\mathrm{t})-(1-l)\left(\mathrm{p}_{1}(\mathrm{t}) \mathrm{b}_{\mathrm{Im}}+p_{4} \hat{b}_{\mathrm{Im}}\right) I_{\mathrm{Im}}-\operatorname{Tax}_{\mathrm{Im}}(\mathrm{t}) \\
\operatorname{Tax}_{\operatorname{Im}}(\mathrm{t})=t_{\operatorname{Im}}\left(\hat{\mathrm{p}}_{1}^{\mathrm{Im}}(\mathrm{t})-\mathrm{p}^{\mathrm{Im}}(\mathrm{t})-\sum_{i=1}^{4} a_{i T r} p_{i}\right) \mathrm{C}_{1}^{\mathrm{Im}}(\mathrm{t})
\end{gathered}
$$

\subsubsection{Banking System}

In this model the banking system is represented by two agents: National Bank and system of commercial banks.

\section{Commercial bank}

Thus we can put down the consolidated balance of commercial banks as:

$$
\begin{aligned}
& \operatorname{Re} s(\mathrm{t})+D^{H}(\mathrm{t})+\sum_{i=1}^{4} M_{i}(\mathrm{t})+M_{G}(\mathrm{t})+\mathrm{L}_{C B}(\mathrm{t})+E_{B}(\mathrm{t})= \\
& M_{B}(\mathrm{t})+\sum_{i=1}^{4} L_{i}(\mathrm{t})+L_{T r}(\mathrm{t})+\mathrm{L}_{\mathrm{Im}}(\mathrm{t})+L^{H}(\mathrm{t})+L_{G}(t)+F_{C B}(\mathrm{t})+\mathrm{D}_{C B}(\mathrm{t})
\end{aligned}
$$

Evaluate the net balance of account deposits and credits of commercial banks in the national bank from the consolidated balance

$$
\begin{aligned}
& D_{C B}-\mathrm{L}_{C B}=\operatorname{Re} s(\mathrm{t})+D^{H}(\mathrm{t})+\sum_{i=1}^{4} M_{i}(\mathrm{t})+M_{G}(\mathrm{t})+E_{B}(\mathrm{t})- \\
& -\left(M_{B}(\mathrm{t})+\sum_{i=1}^{4} L_{i}(\mathrm{t})+L_{T r}(\mathrm{t})+\mathrm{L}_{\operatorname{Im}}(\mathrm{t})+L^{H}(\mathrm{t})+L_{G}(t)+F_{C B}(\mathrm{t})\right)
\end{aligned}
$$

This model supposes that activity of commercial banks system is limited by the following standards:

1. generation of mandatory reserve funds follows the requirements $F_{C B}=\delta_{B}^{F} D^{H}(\mathrm{t})$, where $\delta_{B}^{F}$ is a standard of the population deposits mandatory reserve 
2. limitation (standard) of commercial banks liquidity that require the liabilities are provided by liquid assets $\frac{M_{B}(\mathrm{t})}{\left.D^{H}(\mathrm{t})\right)_{+}+\sum_{i=1}^{4} M_{i}(\mathrm{t})+M_{G}(\mathrm{t})}=\theta_{B}^{1}$

3. standard of capital adequacy $\frac{E_{B}(\mathrm{t})}{\left.D^{H}(\mathrm{t})\right)_{+}+\sum_{i=1}^{4} M_{i}(\mathrm{t})}=\theta_{B}^{2}$

4. creation of reserves for the impaired loans supply $\operatorname{Re} s(t)=h_{1} L_{1}(\mathrm{t})+h_{H} L^{H}(\mathrm{t})$, where $h_{1}$ is the percent of impaired loans to the first sector, and $h_{H}$ is the percent of impaired loans to households Using the described limits we get the following expression for net balance from (1)

$$
\begin{aligned}
& D_{C B}-\mathrm{L}_{C B}=\left(1-\theta_{B}^{1}-\delta_{B}^{F}+\theta_{B}^{2}\right) D^{H}+\left(1-\theta_{B}^{1}+\theta_{B}^{2}\right) \sum_{i=1}^{4} M_{i}(\mathrm{t})+\left(1-\theta_{B}^{1}\right) \mathrm{M}_{G}- \\
& \left.-\left(\sum_{i=2}^{4} L_{i}(\mathrm{t})+L_{G}(t)+L_{T r}(\mathrm{t})+\mathrm{L}_{\mathrm{Im}}(\mathrm{t})+\left(1-h_{1}\right) \mathrm{L}_{1}\right)+\left(1-h_{H}\right) \mathrm{L}_{H}\right)
\end{aligned}
$$

Financial result (change of net worth) of the commercial banks sector is reached by means of incomes from interest of commerce banks assets, liability service charges, profit tax payment at the rate $t_{B}$, salary payments, payment of dividends to employees and to owner of commercial banks $\mathrm{H}_{B}(\mathrm{t})$ and changes of reserves for impaired loans maintenance $\frac{d \operatorname{Re} s(\mathrm{t})}{d t}$

Incomes from the interest of commercial banks asserts are formed by the following elements:

o incomes from consumer loans of the population $r_{b}^{H}\left(1-\mathrm{h}_{H}\right) L^{H}(t), r_{b}^{H}$ is the loan interest rate

o incomes from manufacturing sector loans $r_{B}^{1}\left(1-h_{1}\right) L_{1}(\mathrm{t}), r_{B}^{i} L_{i}(\mathrm{t})(i=2,3,4)$, where $r_{B}^{i}$ is the interest

rate on the $i$ sector of production;

o incomes from trade loans $\mathrm{r}_{T r} L_{T r}(\mathrm{t})$, where $\mathrm{r}_{T r}$ is the interest rate on trade loans;

o incomes from loans of an importer $r_{\mathrm{Im}} L_{\mathrm{Im}}(\mathrm{t})$, where $r_{\mathrm{Im}}$ is the interest rate on importer loans;

o incomes from loans to the government $r_{G} L_{G}(t)$, where $\mathrm{r}_{G}$ is an interest rate on the loans to the

government;

o incomes from commercial banks deposits in the National Bank $r_{C B} \mathrm{D}_{C B}(\mathrm{t})$, where $r_{C B}$ is an interest rate on deposits in the National Bank.

Expenses on liabilities are formed by the following elements:

opayments of interests on the population deposit $\hat{r}_{b}^{H} D^{H}(t)$, where $\hat{r}_{b}^{H}$ is an interest rate on the population deposits;

o payments of interest on loans at the NB $\hat{r}_{c b} L_{c b}(t)$, where $\hat{r}_{c b}$ is an interest rate on loans at the NB.

Thus the net worth could be described by the equation:

$$
\begin{aligned}
& \frac{d E_{B}(\mathrm{t})}{d t}=\left(1-t_{B}\right)\left(r_{B}^{1}\left(1-h_{1}\right) L_{1}(\mathrm{t})+\sum_{i=2}^{4} r_{B}^{i} L_{i}(\mathrm{t})+r_{G} L_{G}(t)+\left(1-h_{H}\right) \mathrm{r}_{B}^{H} L^{H}(\mathrm{t})+r_{C B} \mathrm{D}_{C B}(\mathrm{t})\right)- \\
& -\left(1-t_{B}\right)\left(\hat{r}_{B}^{H} D^{H}(\mathrm{t})+\hat{r}_{C B} L_{C B}(\mathrm{t})+\mathrm{r}_{T r} L_{T r}(\mathrm{t})+\mathrm{r}_{\text {Im }} L_{\text {Im }}(\mathrm{t})\right)-\mathrm{H}_{B}(\mathrm{t})-\frac{d \operatorname{Re} s(\mathrm{t})}{d t}
\end{aligned}
$$


This model assumes that the interest rate on interbank loan is less than the interest rate on the National Bank loan and is bigger than the interest rate on commercial banks deposits in the National Bank. This assumption leaves us consider only net balance of deposits and loans in the National Bank. Then we will suppose that commercial banks system is either a loan debtor of the National Bank and then $L_{C B}>0, D_{C B}=0$, or credit provider of the National Bank and then $L_{C B}=0, D_{C B}>0$. Put it down

$$
\tilde{r}= \begin{cases}r_{C B}, \text { if } & D_{C B}>0, L_{C B}=0, \\ \hat{r}_{C B}, \text { if } & D_{C B}=0, L_{C B}>0 .\end{cases}
$$

After inserting the expression for net balance of deposits and loans of commercial banks in the National Bank and the expression for the impaired loans service reserve into (3.40), we get

$$
\begin{aligned}
& \frac{d E_{B}(\mathrm{t})}{d t}=\left(1-t_{B}\right)\left(\left(1-h_{1}\right)\left(r_{B}^{1}-\tilde{r}\right) L_{1}\left(r_{B}^{1}\right)+\sum_{i=2}^{4}\left(r_{B}^{i}-\tilde{r}\right) L_{i}\left(r_{B}^{i}\right)+\left(r_{G}-\tilde{r}\right) L_{G}(t)+\left(1-h_{H}\right)\left(\mathrm{r}_{B}^{H}-\tilde{r}\right) L^{H}\left(\mathrm{r}_{B}^{H}\right)\right)+ \\
& +\left(1-t_{B}\right)\left(\left(\mathrm{r}_{T r}-\tilde{r}\right) L_{T r}\left(\mathrm{r}_{T r}\right)+\left(\mathrm{r}_{\mathrm{Im}}-\tilde{r}\right) L_{\mathrm{Im}}\left(\mathrm{r}_{\mathrm{Im}}\right)+\left(\left(1-\theta_{C B}^{1}-\delta_{B}^{F}+\theta_{C B}^{2}\right) \tilde{r}-\hat{r}_{B}^{H}\right) D^{H}\left(\hat{r}_{B}^{H}\right)\right)+ \\
& \left(1-\theta_{C B}^{1}-\delta_{B}^{F}+\theta_{C B}^{2}\right) \tilde{r} \sum_{i=1}^{4} M_{i}+\left(1-\theta_{C B}^{1}\right) M_{G}-\mathrm{H}_{B}(\mathrm{t})-\frac{d \operatorname{Re} s(\mathrm{t})}{d t} .
\end{aligned}
$$

Commercial banks maximize their incomes from operations at markets of loans and deposits by setting the interest rates. Note that the expression for the change of commercial banks net worth shows that the choice of interest rates is defined by the completion of independent tasks of revenues optimization

○ from crediting the first sector manufacturers $\left(1-h_{1}\right)\left(r_{B}^{1}-\tilde{r}\right) L_{1}\left(r_{B}^{1}\right)$ by setting the interest rate $r_{B}^{1}$;

- from crediting the manufacturers of $i$ sector $\left(r_{B}^{i}-\tilde{r}\right) L_{i}\left(r_{B}^{i}\right)$ by setting the interest rate

$$
r_{B}^{i}(i=2,3,4)
$$

$\circ \quad$ from crediting households $\left(1-h_{H}\right)\left(r_{B}^{H}-\widehat{r}\right) L^{H}\left(r_{B}^{H}\right)$ by setting the interest rate $r_{B}^{H}$;

- from crediting trade enterprises $\left(\mathrm{r}_{T r}-\tilde{r}\right) L_{T r}\left(\mathrm{r}_{T r}\right)$ by setting the interest rate $\mathrm{r}_{T r}$;

- from crediting the importers $\left(\mathrm{r}_{\mathrm{Im}}-\tilde{r}\right) L_{\mathrm{Im}}\left(\mathrm{r}_{\mathrm{Im}}\right)$ by setting the interest rate $\mathrm{r}_{\mathrm{Im}}$;

$\circ$ from loans at the market of household deposits $\left(\left(1-\theta_{C B}^{1}-\delta_{B}^{F}+\theta_{C B}^{2}\right) \tilde{r}-\hat{r}_{B}^{H}\right) D^{H}\left(\hat{r}_{B}^{H}\right)$ by setting the interest rate $\hat{\mathrm{r}}_{B}^{H}$.

The interest rate $\breve{r}=\operatorname{Arg} \max (r-\tilde{r}) L(r)$ meets the first order requirements

$$
(\breve{r}-\tilde{r}) \frac{d L(\breve{r})}{d r}+L(\breve{r})=0 .
$$

Whence it follows that

$$
\breve{r}=\tilde{r}-\left(L(\breve{r}) / \frac{d L(\breve{r})}{d r}\right)
$$


Requirements for the maximum of the second order are

$$
(\breve{r}-\tilde{r}) \frac{d^{2} L(\breve{r})}{d r^{2}}+2 \frac{d L(\breve{r})}{d r}<0 .
$$

Assume that the interest rate set by commercial banks changes according to the equation

$$
\frac{d r}{d t}=\theta\left(\tilde{r}-\left(L(r) / \frac{d L(r)}{d r}\right)-r\right) .
$$

Note that in case of the steady demand for loans and fixed lending rate is $\tilde{r}$ the interest rate $r=\breve{r}$ is an asymptotically stable equilibrium according to Lyapunov.

Thus we get the following equations for changes of interest rates on loans

$$
\begin{gathered}
\frac{d r_{B}^{i}}{d t}=\theta_{B, i}\left(\tilde{r}-\left(L\left(r_{B}^{i}\right) / \frac{d L\left(r_{B}^{i}\right)}{d r}\right)-r_{B}^{i}\right)(i=1,2,3,4), \\
\frac{d r_{T r}}{d t}=\theta_{B, T r}\left(\tilde{r}-\left(L\left(r_{T r}\right) / \frac{d L\left(r_{T r}\right)}{d r}\right)-r_{T r}\right) \\
\frac{d r_{\mathrm{Im}}}{d t}=\theta_{\mathrm{B}, \mathrm{Im}}\left(\tilde{r}-\left(L\left(r_{\mathrm{Im}}\right) / \frac{d L\left(r_{\mathrm{Im}}\right)}{d r}\right)-r_{\mathrm{Im}}\right)
\end{gathered}
$$

Interest rate $\ddot{r}=\operatorname{Arg} \max \left(\left(1-\theta_{C B}^{1}-\delta_{B}^{F}+\theta_{C B}^{2}\right) \tilde{r}-r\right) D^{H}(\mathrm{r})$ meets the requirements of the first order

$$
\left(\left(1-\theta_{C B}^{1}-\delta_{B}^{F}+\theta_{C B}^{2}\right) \tilde{r}-\ddot{r}\right) \frac{d D^{H}(\ddot{\mathrm{r}})}{d r}-D^{H}(\ddot{r})=0 .
$$

Whence it follows that

$$
\ddot{r}=\left(1-\theta_{C B}^{1}-\delta_{B}^{F}+\theta_{C B}^{2}\right) \tilde{r}-\frac{D^{H}(\ddot{r})}{\frac{d D^{H}(\ddot{\mathrm{r}})}{d r}} .
$$

Requirements for the maximum of the second order are

$$
\left(\left(1-\theta_{C B}^{1}-\delta_{B}^{F}+\theta_{C B}^{2}\right) \tilde{r}-\ddot{r}\right) \frac{d^{2} D^{H}(\ddot{\mathrm{r}})}{d r^{2}}-2 \frac{d D^{H}(\ddot{r})}{d r}<0 .
$$

Assume that the interest rate set by commercial banks changes according to the equation

$$
\frac{d \hat{r}_{B}^{H}}{d t}=\theta_{B, H}\left(\left(1-\theta_{C B}^{1}-\delta_{B}^{F}+\theta_{C B}^{2}\right) \tilde{r}-\frac{D^{H}\left(\hat{r}_{B}^{H}\right)}{\frac{d D^{H}\left(\hat{r}_{B}^{H}\right)}{d r}}-\hat{r}_{B}^{H}\right) .
$$

Note that in case of the steady supply of deposits and fixed lending rate $\tilde{r}$ the interest rate $r_{B}^{H}=\ddot{r}$ is an asymptotically stable equilibrium according to Lyapunov. 


\section{National Bank}

Here is the description of the National Bank (NB) balance.

The NB liabilities are:

- Monetary base, issued by the NB $M(t)$. Monetary base is formed from account balances of all economic agents and from cash money.

- The NB liabilities (loan stocks of the Bank of Kazakhstan, commercial banks deposits in the NB)

- Mandatory reserve funds founded by commercial banks, $F_{c b}(t)$

- The NB reserves $\operatorname{Re} z_{C B}$

The NB assets are:

- The NB loans to commercial banks, $L_{c b}(t)$

- Available assets formed by the NB $A_{c b}(t)$

- Gold and forex reserves GFR ( $t)$

The NB balance ratio could be put down like:

$$
L_{C B}+G F R(\mathrm{t}) \varphi+\mathrm{A}_{C B}(\mathrm{t})=M_{H}(\mathrm{t})+M_{B}(t)+\mathrm{D}_{C B}(\mathrm{t})+\mathrm{F}_{C B}(\mathrm{t})+\operatorname{Re} z_{C B}
$$

The NB currency issue is supposed to happen automatically, i.e. monetary base is formed according to the agents' activity in the economy. Mandatory reserve funds are based on loans provided by commercial banks. Net-liabilities of commercial banks to the NB $\mathrm{D}_{C B}\left(1-\theta_{C B}\right)-L_{C B}$ are based on the consolidated balance of commercial banks. Available assets are proportional to deposits:

$$
\begin{gathered}
\mathrm{A}_{C B}(\mathrm{t})=\theta_{C B} D_{C B}(\mathrm{t})(\mathbf{5 . 6}) \\
G F R(\mathrm{t}) \varphi=\mathrm{M}_{H}(\mathrm{t})+M_{B}(t)+\left(\mathrm{D}_{C B}\left(1-\theta_{C B}\right)-L_{C B}\right)+\mathrm{F}_{C B}(\mathrm{t}) \\
\operatorname{Re} z_{C B}=\widehat{r}_{C B} L_{C B}-r_{C B} D_{C B}+\frac{d \varphi}{d t} G F R
\end{gathered}
$$

\subsubsection{Population}

\section{Description of the Population Consumer Behavior}

Population as an economic agent consumes the production of all brunches. Besides the first sector production competes with similar imported goods at the retail market of nonfood goods. Let's make an assumption that the population demand for the first sector goods is distributed between domestic and imported nonfood goods according to the maximization of the utility function $u\left(C_{1}^{I m}, C_{1}^{I n t}\right)$, where $C_{1}^{I n t}$ is population demand for domestic nonfood product of the first sector in natural units, $C_{1}^{\text {Int }}$ is a demand for imported nonfood product in natural units. The demand for imported product is supposed to be met by importers in the full scale.

The population demand for domestic and imported nonfood goods results from the following expression

$$
u\left(C_{1}^{I m}, C_{1}^{I n t}\right) \rightarrow \max
$$

Financial limits

$$
p_{1}^{I m} C_{1}^{I m}+p_{1}^{I n t} C_{1}^{I n t} \leqslant \phi^{H}-p_{2}^{H} C_{2}-p_{3}^{H} C_{3}-p_{4}^{H} C_{4}=\phi_{1} .
$$

where $C_{i}$ is the population consumption of the i sector production, $p_{i}^{H}$ is a price for production of $\mathrm{i}$ sector set for the population.

$$
C_{1}^{I m} \geqslant 0, C_{1}^{I n t} \geqslant 0
$$

The size of population incomes: 


$$
\phi^{H}=W_{G}+\sum_{i=1}^{4} W_{i}\left(1-t_{C}\right)+\hat{r}_{b}^{H} D^{H}-r_{b}^{H} L^{H}+\tilde{p}_{4} Y_{4}+H_{T r}
$$

where $W_{G}$ is the size of government welfare payments, $W_{i}$ is size of salary payments in i sector, $t_{C}$ is the income tax rate, $\hat{r}_{b}^{H} D^{H}$ are revenues from bank deposits, $r_{b}^{H} L^{H}$ are expenses for bank loans, $\tilde{p}_{4} Y_{4}$ - "shadow" revenues from the forth sector, $H_{T r}$ are revenues/expenses of the retailers.

Volumes of loans and deposits of the population are defined by the model of the population saving behavior.

Take CES function as a utility function:

$$
u(x, y)=\left[A_{1} x^{-\delta}+A_{2} y^{-\delta}\right]^{-\frac{1}{\delta}}, \delta \in[-1,0]
$$

Solving a problem:

$$
\phi_{1}=q\left(p_{1}^{I m}, p_{1}^{I n t}\right) u\left(C_{1}^{I m}, C_{1}^{I n t}\right)
$$

where

$$
\begin{gathered}
q(x, y)=\left[\left(A_{1} x^{\delta}\right)^{\frac{1}{1+\delta}}+\left(A_{2} y^{\delta}\right)^{\frac{1}{1+\delta}}\right]^{1+\frac{1}{\delta}} \\
C_{1}^{I m}=\frac{\phi_{1}}{q\left(p_{1}^{\text {Im }}, p_{1}^{\text {Int }}\right)} \frac{\partial q}{\partial p_{1}^{\text {Im }}} \\
C_{1}^{\text {Int }}=\frac{\phi_{1}}{q\left(p_{1}^{\text {Im }}, p_{1}^{\text {Int }}\right)} \frac{\partial q}{\partial p_{1}^{\text {Int }}}
\end{gathered}
$$

\section{Description of the Population Saving Behavior}

Households interact with commercial banks at the market of loans and deposits. The population has opportunity to raise borrowed assets at the interest rate $r_{L}=r_{b}^{H}$ and to offer its own assets at the rate $r_{D}=\hat{r}_{b}^{H}$.

In oredr to provide the regularity of consumer expenditures $C=p_{1}^{I m} C_{1}^{I m}+p_{1}^{I n t} C_{1}^{I n t}+p_{2}^{H} C_{2}+p_{3}^{H} C_{3}+p_{4}^{H} C_{4}$ the household needs to have a reserve of funds $M(t) \geq \theta C(t)$. Households are granted loans so that at the final point of time they would have been able to pay the loan, i.e. $L(T)=0$.

Assume that household forecasts exponential salary growth $S=W_{G}+\sum_{i=1}^{4} W_{i}\left(1-t_{C}\right)+\tilde{p}_{4} Y_{4}+H_{T r}$ at the rate $\gamma$, i.e. $S(t)=S e^{\gamma t}$

The population welfare at the point of time $t$ is characterized by the value $x=D-L+M$. Alteration of this value is defined by its revenues received as a salary $S(t)$ and payments $D(t) r_{D}$ of deposits $D(t)$, and by expenses that consist of consumer expenses $C(t)$ expenses of loan obligations $L(t) r_{L}$. Assume that the population can immediately redistribute its money from asset of one form to another. In this case the household welfare changes according to the equation

$$
\frac{d x}{d t}=S e^{\gamma t}-C+D r_{D}-r_{L} L
$$


By redistributing its funds the household tends to maximize the benefit of consumtion discounted in time:

$$
\int_{0}^{T} C(t)^{\alpha} e^{-\Delta t} d t \rightarrow \max
$$

Thus the distribution of the population funds is described by optimal control problem

$$
\begin{gathered}
J=\int_{0}^{T}(C(t))^{\alpha} e^{-\Delta t} d t \rightarrow \max \\
\dot{x}=S e^{\gamma t}-C+D r_{D}-r_{L} L, \\
x=D-L+M, M \geq \theta C, D, L, M \geq 0, \\
x(0)=x_{0} x(T) \geq 0 .
\end{gathered}
$$

Note that

$$
\begin{gathered}
x_{1}=\frac{S \theta\left(\Delta-\alpha r_{L}\right)}{\left(r_{L}-\gamma\right)(1-\alpha)\left(1+r_{L} \theta\right)}, \quad \hat{x}=\frac{S \theta}{\gamma \theta+1}, \lambda(\xi)=\frac{S}{\xi-\gamma}, \kappa(\xi)=\frac{(1+\xi \theta)(1-\alpha)}{\theta(\Delta-\alpha \xi)}, \quad \rho=\frac{\Delta+\gamma(1-\alpha)+1 / \theta}{\gamma+1 / \theta}, \\
g(x, y, \xi)=\left[\frac{x-\hat{x}}{y-\hat{x}}\right]^{-\rho}\left(\frac{\gamma \theta+1}{\xi \theta+1} y^{\alpha-1}+\int_{y}^{x} z^{\alpha-1}\left[\frac{z-\hat{x}}{y-\hat{x}}\right]^{\rho} \frac{d z}{z-\hat{x}}\right), \\
h(x, \tau, \xi)=(\lambda(\xi)+x-x \kappa(\xi)) e^{(\gamma-\xi) \tau}+x \kappa(\xi) e^{((\Delta-\xi) /(1-\alpha)+\gamma) \tau}-\lambda(\xi), b(x, \xi)=\frac{1+\xi \theta}{1+\gamma \theta} \int_{0}^{1}(p x+(1-p) \hat{x})^{\alpha-1} p^{\frac{\theta(\Delta-\alpha \gamma)}{\gamma \theta+1}} d p .
\end{gathered}
$$

The problem will be solved in the following way:

1. $\Delta-(1-\alpha) / \theta<r_{D}<r_{L}<\Delta+\gamma(1-\alpha)$

$$
M\left(x_{0}\right)= \begin{cases}\left(x_{0}+\frac{S}{r_{L}-\gamma}\right) \frac{\Delta-\alpha r_{L}}{(1-\alpha)\left(1+r_{L} \theta\right)}, & x_{0}<x_{1}, \\ x_{0}, & x_{0} \in\left[x_{1}, x_{2}\right], \\ x_{2} e^{\left(\frac{\Delta-r_{D}}{1-\alpha}+\gamma\right) \tau_{2}}, & x_{0}>x_{2},\end{cases}
$$

2. $\Delta-(1-\alpha) / \theta<r_{D}<\Delta+\gamma(1-\alpha)<r_{L}$

$$
M\left(x_{0}\right)= \begin{cases}x_{3} e^{\left(\frac{\Delta-r_{L}}{1-\alpha}+\gamma\right) \tau_{3}}, & x_{0}<x_{3}, \\ x_{0}, & x_{0} \in\left[x_{3}, x_{4}\right], \\ x_{4} e^{\left(\frac{\Delta-r_{D}}{1-\alpha}+\gamma\right) \tau_{4}}, & x_{0}>x_{4},\end{cases}
$$

Here $x_{2}$ is the solution of the equation $g\left(x_{2}, x_{1}, r_{L}\right)=\frac{\gamma \theta+1}{r_{D} \theta+1} x_{2}^{\alpha-1}, x_{3}$ is the solution of the equation $b\left(x_{3}, r_{L}\right)=x_{3}^{\alpha-1}, x_{4}$ is the solution of the equation $b\left(x_{4}, r_{D}\right)=x_{4}^{\alpha-1}, \tau_{2}$ is the solution of the equation $h\left(x_{2}, \tau_{2}, r_{D}\right)=x_{0}, \quad \tau_{3}$ is the solution of the equation $h\left(x_{3}, \tau_{3}, r_{L}\right)=x_{0}, \tau_{4}$ is the solution of the equation $h\left(x_{4}, \tau_{4}, r_{D}\right)=x_{0}$.

Loans are determined as $L\left(x_{0}\right)=\left(M\left(x_{0}\right)-x_{0}\right)_{+}$, deposites are determined as $D\left(x_{0}\right)=\left(x_{0}-M\left(x_{0}\right)\right)_{+}$, consumption is determined as $C\left(x_{0}\right)=M\left(x_{0}\right) / \theta$. Volume of loans is positive if $x<x_{1}$ or $x<x_{3}$, volume of deposits is positive if $x>x_{2}$ or $x>x_{4}$.

Volumes of loans $\left(L^{H}=L\right)$ and deposits $\left(D^{H}=D\right)$ of the population are used in the problem of the population 
consumer behavior and in bank balances, cash money on hands of the population $\left(M_{H}=M\right)$ is a part of the NB balance monetary base.

Household has two types of assets - cash money $\mathbf{\square}$ and savings $\left[0, t_{1}\right]$. Household allocates available funds to the current consumption $r_{L}<\Delta+(1-\alpha) \gamma$, interest payments $\left[t_{1}, T\right]$ on the existing loans $\varphi \leq \alpha x^{\alpha-1} /\left(r_{D}+1 / \theta\right)$. Household revenues are composed of salary $\varphi(T)=0$ and dividends from the deposits $\varphi_{u s}\left(x_{0}\right)=\frac{\alpha \theta}{\gamma \theta+1} \int_{0}^{1}\left(p x_{0}+(1-p) \frac{S \theta}{\gamma \theta+1}\right)^{\alpha-1} p^{\frac{\theta(\Delta-\alpha \gamma)}{\gamma \theta+1}} d p$. Values $\varphi=\alpha x^{\alpha-1} /\left(r_{D}+1 / \theta\right)$ and $x=x_{4}$ stand for interest

rate on deposits and loans correspondingly. Assume that household forecasts exponential growth of the salary $x<x_{4}$ with the rate $x>x_{4}$, i.e. $\sigma>0$. In order to provide regularity of consumer costs $d V / d x$ it is necessary to have monetary reserve $\frac{d V}{d x}=\alpha \int_{0}^{\infty}\left(\frac{S \theta}{\gamma \theta+1}+\left(y-\frac{S \theta}{\gamma \theta+1}\right) e^{-(\gamma+1 / \theta) t}\right)^{\alpha-1} e^{-(\Delta+1 / \theta+(1-\alpha) \gamma) t} d t$. Let's take value $t_{2}$ for the liquidity ratio.

The household maximizes profitability of the further consumption discounted at the coefficient $x_{0}>x_{r_{D}}$.

Take $x_{0} \geq x_{2}, t_{2}=0, M_{r L}=\left(x+w_{r L}\right) / \kappa(r L), x(t),\left[0, t_{2}\right], x(t), x<\tilde{x}$.

Statement 1. Assume that requirements for the solution existence are met and $a=\left(1+r_{L} \theta\right)(1-\alpha) /\left(\theta\left(\Delta-\alpha r_{L}\right)\right)$.

Then the equation $x_{1}=\frac{S \theta\left(\Delta-\alpha r_{L}\right)}{\left(r_{L}-\gamma\right)\left(1-\alpha+\theta\left(r_{L}-\Delta\right)\right)}, \tau_{1}(x)=\frac{\theta}{\gamma \theta+1} \ln \left(\left(x-\frac{S \theta}{\gamma \theta+1}\right) /\left(x_{1}-\frac{S \theta}{\gamma \theta+1}\right)\right)$. has a positive solution $x_{1}>S \theta /(\gamma \theta+1)$. Besides for any $\Delta-(1-\alpha) / \theta<r_{L}<\Delta+(1-\alpha) \gamma$, more than $\Delta-\alpha \gamma>0$, there is a solution $r_{L}>\gamma$ of the equation $\tau_{1}(x)$.

Statement.2. Assume that requirements for the solution existence are met and $r_{L}>\gamma$. Then the equation $\forall$ has a solution. Besides if $x_{0} \geq 0$ is a solution where $T, t_{1}$ is a solution where $x_{0} \leq x_{1} u t_{1}=0$, then $x_{0}>x_{1}$. Specify the solution $\forall$ if $\xi=r_{L}$ as $x_{3}$, if $\xi=r_{D}$ as $x_{4}$.

Statement 3. Assume that requirements for the solution existence are met and $\left[t_{1}, T\right]$. Then $x(T)=0$, there is a solution $\hat{\varphi}(x)$ for the equation $x \leq \tilde{x}=S /\left(\left(r_{L}-\Delta\right) /(1-\alpha)+1 / \theta\right)$.

Statement 4. Assume that requirements for the solution existence are met and $x$. Then $\tilde{x}$, there is a solution $\left.\dot{x}\right|_{x=\tilde{x}}<0$ for the equation $x_{0}>\tilde{x}$.

\section{Identification:}

\section{Saving households:}

\section{Discussion}

$$
T \leq \ln \left(M_{4}\left(T_{4}\right) / x_{0}\right) /\left(\left(r_{L}-\Delta\right) /(1-\alpha)-\gamma\right)
$$

Today one of the most actively discussed national problems is the rise of Kazakhstan economy investment attrectiveness. Moreover the investments are required not only for the development of depressed manufacturing brunches but also for the relatively successful power-generating sectors. Oil complex, for example, needs investments to maintain the level of hydrocarbon production, electric energy sector has an urgent problem of renovating the old capacities.

In order to make a reasonable investment model of any econmic sector it is necessary first of all to learn how to evaluate the primary parameter that defines the investment activity or in other words the profitability of investments. Problem of evaluation of profitability and efficiency of investments is one of the major problems in the sphere of corporate finances. Works by I. Fisher $(3,4)$ are considered to be the founders of scientific 
discussion of the problem. Then works by D. Hirshleifer (5), R.M. Solow (6), D. Gale (7), R. Dorfman (8) continued the discussions on this issue. Two indicators were generaly offered for the profitability evaluation; that is NPV - net present value of cashflows connected to the project and IRR - internal rate of return at which project's NPV reduces to 0 . It is necessary to mention that there were arguments pro and contra every indicator. Moreover the authors often reasoned their opinion by notorious "easiness" of usage in practice.

D.G. Cantor and S.A. Lipman in (9) have offered the statement of the problem which gave them opportunity to justify the usage of the indicator (and a unified pattern of its calculation) IRR for the evaluation of investment projects profitability and to show its connection to NPV. It is interesting that the authors haven't justified the privilege of the first indicator. In (9) there is a formular of the investor's objective that posesses common premises. This objective gives opportunity to control the speed of investment projects implementation in an attempt to receive a maximum final income. Investment rate at the widening investment horizon was accepted as the investment profitability evaluation. It turned out that it is possible to calculate this value explicitly for a wide range of investment projects and that this value corresponds to IRR. Thus the profitability evaluation was formed in a natural way as a result of an analysis of the investor's initial objective completion.

Cantor-Lipman approach turned out to be fruitful. Statements of problems offered by D.G. Cantor and S.A. Lipman are discussed in works by I.M. Sonin and E.L. Presman $(10,11)$. (10) reasons the results of (9) by the instrument of dynamic programming. In (11) there is an interpretation of the investment polyniminal positive roots that are distinct from maximum (connected to IRR). In (12) D.G. Cantor and S.A. Lipman expand their approach to the case with several projects and reason the profitability indicator for the whole pool of investment projects. In works $(13,14)$ by B.Z. Belenkiy the investment activity is described as a part of linear model of Neiman-Gale and the problem of the investment projects profitability evaluation is narrowed down to the question of existance of a mainline in the model of Neiman-Gale. In (15) the model of Cantor-Lipman was expanded: they considered a situation where there is a subjective (from investor's point of view) chance on fading of the demand on investments and the investor is not allowed to take short positions. In such statement the problem was brought to the analysis of Bellman equation. In (16) there were found the ratios of model's parameters at which investor's effective behavior is a cautious strategy that excludes bankruptsy. In (17) the authors created low-bound evaluations of the capital increase rate of the investor who uses a cautious investment strategy.

Works by D.G. Cantor and S.A. Lipman and works that followed their ideas were oriented on the analysis of investments in conditions of discrete time and for that reason they dealt with investment projects which payment flows were equally distributed according to arrival time. This are quite restrictive conditions for modelling actual investment projects in applied models. Payment flows often arrive at nonmeasurable intervals. Intuitive approach, at which a uniform structure (with sufficient number of zero payment flows) approximated such payment structure, leads to a serious reduction of a time step. Thus additional difficulties in calculation appear, because it is necessary to reduce a time step in the whole model. That is why a transition to continious time is natural. Thus we will get an opportunity to use the Cantor-Lipman approach for the analysis of investments in macroeconomical models that are often formed in continious time for ease of analysis. For example the modelling of investment activity of real economic sector is a topical problem for systemic approach to modelling Kazakhstan economy $(16,17)$.

\section{Conclusion}

The strategy of mathematical modeling of the Republic of Kazakhstan was developed. Statistics of the basic economic indicators was collected and studied. The economic model was created and the procedure for settling its course was implemented. A number of analytical and prediction calculations was made.

The developed model is one of the most difficult types of mathematical models of economy; it is a model of intertemporal economic balance. This means that economic dynamics is described as a result of interaction between the stated economic agents. The most significant scientific achievement of this work is the fact that this approach provides a quite satisfactory description of economic processes even under the conditions of a crisis.

Analysis of the developed model of Kazakhstan economy has proved that in order to find a tool for medium-term and long-term forecasting it is necessary to make new clusters of the model that would take into account long-term aspects of economic agents' behavior.

That is the reason why we have begun to study the development of separate clusters of the model which to our opinion are essential for the aims of medium-term and long-term forecasting. On the basis of the research we have singled out three key problems of systemic analysis of Kazakhstan economy in long-term perspective: 
- Problem of production modeling in Kazakh industries with low competitiveness in view of scarcity of working capital;

- Problem of description of investment activity in fuel and energy complex;

- Problem of medium layer formation in the process of modeling the population saving behavior.

The developed model could be used to forecast the changes of macroeconomic indicators and to study the way they are influenced by economic policy.

\section{References}

Belenkiy, V. (2002). Economic dynamics: analysis of capital projects as a part of linear model of Neiman-Gale. Moscow: TEMI RAN, preprint 137.

Belenkiy, V. (2007). Optimization model of economic dynamics. Conceptual framework. One-dimensional models. Bellman's approach. Moscow: Science.

Bikkinina, L., \& Shananin, A. (n.d.). To the theory of the investment projects profitability in the context of imperfect financial market. XLVI MIPT conference, 136-137.

Cantor, D., \& Lipman, S. (1983). Investment selection with imperfect capital markets. Econometrics, 4(51), 1121-1144.

Cantor, D., \& Lipman, S. (1995). Optimal Investment Selection with a Multitude of Projects. Econometrics, 5(63), 1231-1240.

Dorfman, R. (1981). The meaning of internal rates of return. J. of Finance, 5(36), 1011-1021.

Fisher, I. (1907). The rate of interest. New York: Macmillan Co.

Fisher, I. (1930). The theory of interest. New York: Macmillan Co.

Gale, D. (1973). On the theory of interest. The American mathematical monthly, 8(80), 853-868.

Hirshleifer, J. (1958). On the theory of optimal decision. J. of political economy, 66, 229-239.

Petrov, A., Pospelov, I., \& Shananin, A. (1996). Experience of economy mathematic modeling. Moscow: Energoatomizdat.

Petrov, A., Pospelov, I., \& Shananin, A. (1999). From State plan to non-efficient market. Mathematical analysis of Russian economic structures. New York, Lewinston: The Edwin Mellen Press.

Presman, E., \& Sonin, I. (2000). Growth rate, internal rates of return and financial bubbles. Moscow: CEMI Russian Academy of Sciences, preprint 103.

Solow, R. (1963). Capital theory and the rate of return. Amsterdam: North Holland Press.

Sonin, I. (1995). Growth rate, internal rates of return and turn pikes in an investment model. Economic theory, 5 , 383-400.

Vaschenko, M. (2006). Study of Bellman equation in the problem of optimal investment. Cl. of articles of young scientists of CM\&C faculty of MSU, Moscow, 3, 32-43.

Vaschenko, M. (2009). Evaluation of investment projects profitability in uncertain conditions. Mathematical modeling, 3(21), 18-30.

Website of the Agency of the Republic of Kazakhstan for Regulation and Supervision of Financial Market and Institution. (n.d.). Retrieved January 25, 2014, from http://www.afn.kz/.

Website of the National Bank of the Republic of Kazakhstan. (n.d.). Retrieved January 25, 2014, from http://www.nationalbank.kz/.

Website of the Statistical Agency of the Republic of Kazakhstan. (n.d.). Retrieved January 25, 2014, from http://www.stat.kz/.

\section{Copyrights}

Copyright for this article is retained by the author(s), with first publication rights granted to the journal.

This is an open-access article distributed under the terms and conditions of the Creative Commons Attribution license (http://creativecommons.org/licenses/by/3.0/). 